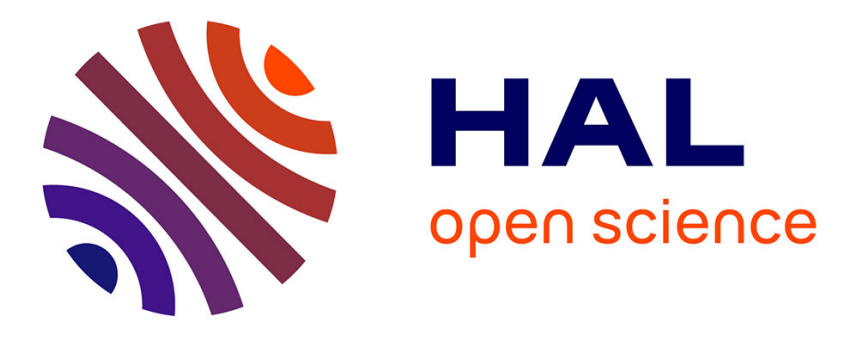

\title{
The high efficacy of muscarinic M4 receptor in D1 medium spiny neurons reverses striatal hyperdopaminergia
}

Anu G Nair, Liliana Castro, Marianne El Khoury, Victor Gorgievski, Bruno Giros, Eleni T. Tzavara, Jeanette Hellgren-Kotaleski, Pierre Vincent

\section{To cite this version:}

Anu G Nair, Liliana Castro, Marianne El Khoury, Victor Gorgievski, Bruno Giros, et al.. The high efficacy of muscarinic M4 receptor in D1 medium spiny neurons reverses striatal hyperdopaminergia. Neuropharmacology, 2019, 146, pp.74-83. 10.1016/j.neuropharm.2018.11.029 . hal-02177391

\section{HAL Id: hal-02177391 https://hal.sorbonne-universite.fr/hal-02177391}

Submitted on 8 Jul 2019

HAL is a multi-disciplinary open access archive for the deposit and dissemination of scientific research documents, whether they are published or not. The documents may come from teaching and research institutions in France or abroad, or from public or private research centers.
L'archive ouverte pluridisciplinaire HAL, est destinée au dépôt et à la diffusion de documents scientifiques de niveau recherche, publiés ou non, émanant des établissements d'enseignement et de recherche français ou étrangers, des laboratoires publics ou privés. 


\section{THE HIGH EFFICACY OF MUSCARINIC M RECEPTOR IN DI \\ MEDIUM SPINY NEURONS REVERSES STRIATAL}

\section{HYPERDOPAMINERGIA.}

Authors: Anu G. Nair ${ }^{1,2,3^{*}}$; Liliana R.V. Castro ${ }^{4,5}$; Marianne El Khoury ${ }^{5,6}$; Victor Gorgievski ${ }^{5,6}$; Giros, Bruno ${ }^{5,6,7}$; Eleni T. Tzavara ${ }^{5,6}$; Jeanette Hellgren-Kotaleski1 ${ }^{1,8}$; Pierre Vincent ${ }^{4,5}$.

Corresponding author: Pierre Vincent; pierre.vincent@upmc.fr; UMR8256 "Biological Adaptation and Ageing", Institut de Biologie Paris-Seine (IBPS), 7 quai Saint Bernard, F-75005 Paris, France.

Running title: Efficient cAMP inhibition by striatal $\mathrm{M}_{4}$ receptors

Keywords: Acetylcholine; Dopamine; Biosensor imaging; Cyclic AMP; Striatum; Muscarinic receptors; $\mathrm{M}_{4}$ receptor

\section{Author Affiliation:}

${ }^{1}$ Science for Life Laboratory, School of Computer Science and Communication, KTH Royal Institute of Technology, Stockholm, Sweden;

${ }^{2}$ National Centre for Biological Sciences, Tata Institute of Fundamental Research, Bangalore, India;

${ }^{3}$ Manipal University, Manipal, India;

${ }^{4}$ Sorbonne Université, CNRS, Biological Adaptation and Ageing, F-75005 Paris, France;

${ }^{5}$ Member of the Bio-Psy Labex.

${ }^{6}$ Sorbonne Université, CNRS, Neuroscience Paris Seine, F-75005 Paris, France.

${ }^{7}$ Department of Psychiatry, Douglas Mental Health University Institute, McGill University Faculty of Medicine, Montreal, Quebec, Canada

${ }^{8}$ Department of Neuroscience, Karolinska Institutet, Solna, Sweden;

*: present address : Institute of Molecular Life Sciences, University of Zurich, Winterthurerstrasse 190, 8057 Zurich, Switzerland

This article is also published as: Nair, Castro, El Khoury, Gorgievski, Giros, Tzavara, Hellgren-Kotaleski et Vincent (2018). "The high efficacy of muscarinic M4 receptor in D1 medium spiny neurons reverses striatal hyperdopaminergia" Neuropharmacology, http:// dx.doi.org/10.1016/j.neuropharm.2018.11.029

(C) 2018. This manuscript version is made available under the CC-BY-NC-ND 4.0 license http://creativecommons.org/licenses/by-nc-nd/4.0/ 


\section{ABSTRACT}

The opposing action of dopamine and acetylcholine has long been known to play an important role in basal ganglia physiology. However, the quantitative analysis of dopamine and acetylcholine signal interaction has been difficult to perform in the native context because the striatum comprises mainly two subtypes of medium-sized spiny neurons (MSNs) on which these neuromodulators exert different actions. We used biosensor imaging in live brain slices of dorsomedial striatum to monitor changes in intracellular cAMP at the level of individual MSNs. We observed that the muscarinic agonist oxotremorine decreases cAMP selectively in the MSN subpopulation that also expresses $\mathrm{D}_{1}$ dopamine receptors, an action mediated by the $\mathrm{M}_{4}$ muscarinic receptor. This receptor has a high efficacy on cAMP signaling and can shut down the positive cAMP response induced by dopamine, at acetylcholine concentrations which are consistent with physiological levels. This supports our prediction based on theoretical modeling that acetylcholine could exert a tonic inhibition on striatal cAMP signaling, thus supporting the possibility that a pause in acetylcholine release is required for phasic dopamine to transduce a cAMP signal in D1 MSNs. In vivo experiments with acetylcholinesterase inhibitors donepezil and tacrine, as well as with the positive allosteric modulators of $\mathrm{M}_{4}$ receptor VU0152100 and VU0010010 show that this effect is sufficient to reverse the increased locomotor activity of DAT-knockout mice. This suggests that $\mathrm{M}_{4}$ receptors could be a novel therapeutic target to treat hyperactivity disorders.

\section{HIGHLIGHTS}

- Muscarinic receptor activation decreases cAMP only in D1-type striatal neurons

- The M4 muscarinic receptor is the likely mediator of this effect

- Extremely low levels of acetylcholine are sufficient to trigger this effect

- Cholinergic neurons can thus control dopamine action in the striatum

- M4 pharmacology revert hyperlocomotion in a genetic mouse model of hyperactivity 


\section{INTRODUCTION}

Cholinergic and dopaminergic systems perform in a dynamic equilibrium and disruption of this equilibrium is correlated with a number of disorders in the central nervous system (Hoebel et al., 2007; Calabresi et al., 2006; Cragg, 2006; Aosaki et al., 2010; Lester et al., 2010). Acetylcholine is involved in various striatum-dependent behaviors, and aberrations in cholinergic signaling result in severe behavioral deficits (Jeon et al., 2010; Aoki et al., 2015; Maurice et al., 2015). Deficits in cholinergic neuromodulation has also been linked to Parkinson's disease (Perez-Lloret \& Barrantes, 2016). Striatal acetylcholine is primarily released by cholinergic interneurons spread across striatum, which represent only a small fraction ( $2 \%$ ) of overall striatal neuronal population (Bolam et al., 1984; Contant et al., 1996). These neurons are tonically active $(\sim 5 \mathrm{~Hz})$ and are believed to maintain a basal level of acetylcholine in the striatum (Aosaki et al., 1995). Despite their scarcity, cholinergic interneurons have a widespread coverage of the striatum with their dense and complex axonal arborization (Contant et al., 1996), and could strongly regulate striatal physiology (Shen et al., 2015). These cholinergic interneurons exhibit diverse activity patterns depending on behavioral states, most notably a pause in activity in response to a salient stimulus or reward (Aosaki et al., 1994).

An important target of striatal acetylcholine is the medium-sized projection neuron (MSN), which expresses muscarinic acetylcholine receptors. The two MSN classes, $\mathrm{D}_{1^{-}}$ expressing (D1 MSNs) and $\mathrm{D}_{2}$-expressing MSNs (D2 MSNs), show differential expression of muscarinic receptor-types, with the $\mathrm{M}_{4}$-type expression mostly restricted to the $\mathrm{D}_{1} \mathrm{MSNs}$ and the $\mathrm{M}_{1}$ receptors being expressed in both D1 and D2 MSNs (Hersch et al., 1994; Ince et al., 1997). These receptors belong to the superfamily of G-protein-coupled receptors. $M_{1}$ is primarily coupled to $G_{q / 11}$ and stimulates the Protein Kinase $C$ and inositol tris-phosphate pathway, while $\mathrm{M}_{4}$ is coupled to $\mathrm{G}_{\mathrm{i} / \mathrm{o}}$ and mediates inhibition of adenylyl cyclase activity.

The cAMP/PKA signaling pathway plays a central role in the striatum in the integration of the dopamine signal, and activation of $\mathrm{M}_{4}$ receptors significantly affects various dopamine-dependent behaviors. For example, $\mathrm{M}_{4}$ receptor knockout in D1 MSNs results in increased dopamine-dependent phenotypes, such as hyper-locomotion, an effect possibly mediated through the cAMP signaling pathway (Jeon et al., 2010), whereas a positive allosteric modulator (PAM) of $\mathrm{M}_{4}$ receptor reverses amphetamine-induced hyper-locomotion (Brady et al., 2008). $\mathrm{M}_{4}$-dependent cAMP inhibition which opposes $\mathrm{D}_{1}$ action has also been implicated in striatal synaptic plasticity in a mouse model of L-DOPA-induced dyskinesia (Shen et al., 2015). However, the physiological role and the state of muscarinic receptordependent cAMP signaling in MSNs still remains unclear.

We previously used computational modeling of striatal intracellular signaling to analyze the physiological consequences of $\mathrm{M}_{4}$ receptor activation by the tonic firing of cholinergic interneurons. Our simulations suggested that, by suppressing cAMP signaling under basal condition, $\mathrm{M}_{4}$ receptor reduces noisy corticostriatal synaptic changes in D1 MSNs (Nair et al., 2015). According to this hypothesis, dopamine-dependent cAMP signaling in D1 MSNs is thought to be under tonic inhibition by $\mathrm{M}_{4}$ receptors, and this inhibition is transiently relieved by a pause in the cholinergic activity, thus setting-up a time-window in which dopamine could activate cAMP signaling and induce long-term potentiation of corticostriatal synapses on D1 MSNs (Nair et al., 2015). However, there are two main 
prerequisites that are central to this hypothesis: (1) the activity of $\mathrm{M}_{4}$ receptors should be powerful enough to strongly inhibit striatal cAMP signaling, and (2) the level of tonic acetylcholine produced under basal condition should be sufficient to maintain this $\mathrm{M}_{4}$ receptor activity. However, due to the lack of quantitative characterization of the efficacy of striatal muscarinic receptors on cAMP signaling, especially in intact MSNs, it is not clear to what extent this scenario is physiologically valid.

We used FRET-based cAMP biosensor expressed in mouse brain slice to characterize the efficacy of muscarinic receptor activation on the cAMP signaling in MSNs. Our imaging results show that the activation of muscarinic receptors completely inhibits cAMP signaling in MSNs, specifically D1 MSNs. This inhibition is fully mediated by muscarinic $\mathrm{M}_{4}$-type receptor. This muscarinic inhibitory effect is also functionally coupled to $\mathrm{D}_{1}$-dependent cAMP signaling. Even a low level of acetylcholine reduces efficiently the downstream signal triggered by transient dopamine inputs. Taken together, our data support the possibility that $\mathrm{M}_{4}$ receptor activation under basal condition due to the tonic activity of cholinergic interneurons results in the tonic suppression of cAMP signaling in D1 MSNs. Finally, we show that this powerful mechanism is sufficient to completely reverse the hyperdopaminergic behavioral aberrations observed in the DAT knockout mouse model of hyperactivity disorder. 


\section{MATERIALS AND METHODS}

\section{Animals}

Biosensor imaging experiments were performed with 8-12 days old C57Bl/6J mice obtained from Janvier (Le Genest Saint Isle, France). Breeding and genotyping of DAT wildtype and knockout mice was done as previously described (Tzavara et al., 2006). The animals were treated according to the regulations of Sorbonne Universite animal care committee and the French Ministry of Agriculture and Forestry guidelines for handling animals.

\section{Brain slice preparation}

The protocol has been described previously in more details (Yapo et al., 2017). Briefly, animals were killed by decapitation and the brain quickly dissected and placed in ice-cold slicing solution saturated with $5 \% \mathrm{CO}_{2}$ and $95 \% \mathrm{O}_{2}$. The slicing solution was composed of: $125 \mathrm{mM} \mathrm{NaCl}, 0.4 \mathrm{mM} \mathrm{CaCl}_{2}, 1 \mathrm{mM} \mathrm{MgCl}_{2}, 1.25 \mathrm{mM} \mathrm{NaH}_{2} \mathrm{PO}_{4}, 26 \mathrm{mM} \mathrm{NaHCO}_{3}, 5 \mathrm{mM}$ sodium pyruvate, $20 \mathrm{mM}$ glucose and $1 \mathrm{mM}$ kynurenic acid. Coronal slices of $300 \mu \mathrm{m}$ thickness were cut with a vibrating blade microtome (VT1200S, Leica) in ice-cold solution. Slices were kept in the same solution at room temperature for around 30 minutes, then transferred onto Millicell-CM membrane (Millipore) placed over culture medium (50\% MEM media, $50 \%$ HBSS, 6.5 g/l glucose, penicillin-streptomycin; Invitrogen). The slices were incubated overnight at $35^{\circ} \mathrm{C}$ and $5 \% \mathrm{CO}_{2}$ and infected with the Sindbis vector to express the biosensor (Polito et al., 2013; Ehrengruber et al., 1999).

\section{Brain slice imaging}

Live imaging was performed on brain slices which expressed the cAMP-specific EpacS $\mathrm{S}^{\mathrm{H} 150}$ biosensor (Polito et al., 2013). Slices were kept at room temperature in the recording solution saturated with $5 \% \mathrm{CO}_{2}$ and $95 \% \mathrm{O}_{2}$ for around 30 minutes before imaging. The composition of the recording solution was the same as the slicing solution except that it contained no kynurenic acid and $\mathrm{CaCl}_{2}$ was $2 \mathrm{mM}$. The slice was imaged in a temperature controlled $\left(32^{\circ} \mathrm{C}\right)$ recording chamber and continuously perfused at $2 \mathrm{ml} / \mathrm{min}$ using a peristaltic pump. The same perfusion system was used to apply drugs onto the recorded slice. All imaging experiments were done in presence of $200 \mathrm{nM}$ tetrodotoxin, to inhibit endogenous electrical activity, and the following inhibitors of receptors: CGP-55845A (100 $\mathrm{nM}$; GABA $\mathrm{B}_{\mathrm{B}}$ antagonist), AM-251(100 nM; $\mathrm{CB}_{1}$ antagonist) and naloxone (500 nM; opioid receptor antagonist).

Two-photon imaging was performed using a custom-built two-photon laser scanning setup based on an Olympus BX51WI upright microscope with a 40X 0.8 NA water immersion objective. Donor and acceptor images were obtained for donor excitation with a Ti:sapphire laser (MaiTai HP, Spectra-Physics) tuned at $850 \mathrm{~nm}$ wavelength. A filter cube containing a dichroic mirror (FF506-Di02-25x36, Semrock) and two emission filters (FF01-479/40 and FF01-542/50, Semrock) was used to separate the donor and acceptor emission wavelengths which were simultaneously detected using photomultipliers (H9305, Hamamatsu). The image acquisition process was controlled using MPscope software (Nguyen et al., 2006). Image stacks (vertical interval of either 0.5 or $1 \mu \mathrm{m}$ ) were acquired for 
every time point.

Wide field imaging was performed using Olympus BX50WI or BX51WI upright microscopes with a 40X $0.8 \mathrm{NA}$ water immersion objective. The donor excitation was provided by an LED source (420 nm diode, Mightex) with a HC434/17 excitation filter (Semrock). The dichroic mirror was BS452 (Semrock). Two images were acquired for every data point by alternating filter for donor (HC479/40) and acceptor (HC542/50 both from Semrock) emission with a filter wheel (Sutter Instruments). Images were acquired using an ORCA-AG camera (Hamamatsu). Image acquisition was controlled using iVision software (Biovision). In dopamine uncaging experiments, an ultraviolet (UV) LED source (360 nm diode, Mightex) mounted on the epifluorescence port was used for uncaging. UV illumination was done for $1 \mathrm{~s}$ duration with a power of $7.5 \mathrm{~mW}$, as measured at the exit of the objective.

\section{Data analysis}

Data analysis was done with custom routines written in IGOR Pro (Wavemetric) following the previously described protocol (Polito et al., 2014; Yapo et al., 2017). FRET changes were quantified using ratio of images from donor and acceptor channels for each data point. Corrections for non-uniform illumination, movement and channel mis-registration were done prior to ratio calculation. No corrections for bleed-through or cross-excitation were applied. The ratio value for a region-of-interest (ROI) was calculated by averaging all the individual pixels included in that ROI, weighted by their intensity. In the case of twophoton microscopy, ratio values were averaged for 1-2 images above and below the plane containing the ROI in the stack. Cells which had clear neuronal morphology, smooth surface contour and responded to either $\mathrm{D}_{1}$ or $\mathrm{A}_{2}$ agonists were thus identified as MSNs and used in our analysis. $\mathrm{N}$ indicates the number of brain slices, and $\mathrm{n}$ indicates the number of neurons.

\section{Behavior}

Assessment of locomotor activity in DAT wild-type and knockout mice was performed as previously described (Tzavara et al., 2006). To assess pharmacological effects of cholinergic compounds injected intraperitoneally, mice were placed on the actimeter $20 \mathrm{~min}$ after injection and locomotor activity was measured for a total of $60 \mathrm{~min}$. For intrastriatal drug infusion, mice were implanted with guide cannulas as previously described (Apazoglou et al., 2018). Mice were anesthetized with a ketamine/xylazine mixture (100/10 mg/kg, i.p.) and stereotaxically implanted with $12 \mathrm{~mm}$ long cannulae in the left and right striatum (AP +1.6; $\mathrm{ML}+/-1.0$; DV - 2.5). Animals were left to recover for at least 3 days. On the test day, infusion needles (30 Gauge) were inserted into the cannulae (needles were $13 \mathrm{~mm}$ long, i.e. ending $1 \mathrm{~mm}$ deeper than the guide cannula) and mice were locally injected, with the help of a pump (UNIVENTOR) at a rate of $0.5 \mu \mathrm{l} / \mathrm{min}$ either with VU0010010 $(1 \mu \mathrm{g} / \mu \mathrm{l})$ or vehicle ( $80 \%$ saline $+10 \%$ DMSO $+10 \%$ cremophor). The needles were then left in place for another 2 min to ensure compound diffusion. Mice were subsequently placed 10 min after injection in the actimeter for $60 \mathrm{~min}$. 


\section{Drugs}

Acetylcholine hydrochloride, neostigmine bromide and the compounds for slicing/ recording solutions were purchased from Sigma-Aldrich (St Quentin-Fallavier, Isère, France). TTX was purchased from Latoxan (Valence, France). Donepezil was a gift from Eisai to ETT. NPEC-DA: (N)-1-(2-Nitrophenyl)ethylcarboxy-3,4-dihydroxyphenethylamine and all other drugs were obtained from Tocris Bio-techne (Lille, France). Table 1 recapitulates the drugs used in these experiments.

\begin{tabular}{|l|l|l|}
\hline Drugs & $\begin{array}{l}\text { concentration } \\
(\boldsymbol{\mu M})\end{array}$ & Description \\
\hline oxotremorine & 1 & $\begin{array}{l}\text { Non-specific muscarinic receptor } \\
\text { agonist. }\end{array}$ \\
\hline atropine & 2 & $\begin{array}{l}\text { Non-specific muscarinic receptor } \\
\text { antagonist. }\end{array}$ \\
\hline tropicamide & 1 & Muscarinic $\mathrm{M}_{4}$ receptor antagonist. \\
\hline VU0255035 & 0.5 & Muscarinic $\mathrm{M}_{1}$ receptor antagonist. \\
\hline acetylcholine & 0.1 & Natural agonist of muscarinic receptors. \\
\hline neostigmine, donepezil, \\
tacrine & & Acetylcholinesterase inhibitors. \\
\hline VU0152100, VU0010010 & & $\begin{array}{l}\text { Positive allosteric modulator }(\mathrm{PAM}) \text { of } \\
\mathrm{M}_{4} \text { receptor. }\end{array}$ \\
\hline SKF-81297 & D -like receptor agonist. \\
\hline quinpirole & 0.1 & $\mathrm{D}_{2}$-like receptor agonist. \\
\hline forskolin & 1 & Adenylyl cyclase activator. \\
\hline IBMX & 12,5 & $\begin{array}{l}\text { Non-specific phosphodiesterase } \\
\text { inhibitor. }\end{array}$ \\
\hline
\end{tabular}

Table 1: Drugs used in these experiments. The concentration indicated in the table is the commonly used concentration, unless stated otherwise. 


\section{RESULTS}

\section{Muscarinic receptor activation selectively inhibits cAMP signaling in D1 MSNs}

MSNs express high levels of muscarinic receptors (Hersch et al., 1994; Yan et al., 2001) and we first determined how muscarinic receptor activation affected the cAMP signaling pathway in the D1 and D2 MSN sub-populations. Our previous work showed that the functional responses to $\mathrm{D}_{1}$ and $\mathrm{D}_{2}$ agonists are strictly segregated on these D1 and D2 neuronal subtypes (Yapo et al., 2017). Here, we used a similar protocol where striatal brain slices expressing the cAMP biosensor Epac-S ${ }^{\mathrm{H} 150}$ were imaged with a two-photon microscope. Bath application of the $\mathrm{D}_{1}$ receptor agonist SKF-81297 (SKF, $0.1 \mu \mathrm{M}$ ) increased Epac- $\mathrm{S}^{\mathrm{H} 150}$ ratio selectively in a sub-population of MSNs, thus identified as the D1 MSNs (Figure 1). A low dose of the adenylyl cyclase activator forskolin (fsk, $0.5 \mu \mathrm{M}$ ) was then applied to induce a steady-state increase in cAMP level in all MSNs. Application of the generic muscarinic agonist, oxotremorine $(1 \mu \mathrm{M})$, robustly reduced cAMP level selectively in this D1 MSN subpopulation, while no effect was observed in the other sub-population. Application of the $\mathrm{D}_{2}$ agonist quinpirole $(1 \mu \mathrm{M})$ decreased cAMP in the other MSNs, confirming that this other subpopulation was the D2 MSNs.

Out of 4 repetitions of this protocol, all the D1 MSNs (53 neurons) showed a negative cAMP response to oxotremorine stimulation whereas none of the D2 MSNs (36 neurons) showed any response to the activation of muscarinic receptors. This result shows that, in the dorsal striatum, activation of muscarinic receptors decreases cAMP selectively in the $D_{1}$ subpopulation of MSNs.

\section{Muscarinic inhibition of cAMP in D1 MSNs is mediated by $\mathrm{M}_{4}$ receptors}

MSNs express both $\mathrm{M}_{1}$ and $\mathrm{M}_{4}$ type muscarinic receptors (Bernard et al., 1992; Hersch et al., 1994; Sánchez-Lemus \& Arias-Montaño, 2006) and both receptors could act on cAMP signaling, either directly, via $\mathrm{G}_{\mathrm{i} / \mathrm{o}}$, or indirectly, via intracellular calcium. Therefore, we used pharmacology to assess the contribution of each receptor subtype in the effect of oxotremorine on cAMP. These experiments and the following were performed with widefield imaging. The cAMP level was first increased by the application of a low concentration of forskolin (low fsk, $250 \mathrm{nM}$ ). On this steady-state cAMP level, addition of oxotremorine $(500 \mathrm{nM})$ produced a large and sustained decrease in cAMP in the D1 MSNs. At the end of the experiment, application of quinpirole $(1 \mu \mathrm{M})$ followed by SKF-81297 $(0.1 \mu \mathrm{M})$ was used to identify D1 and D2 MSNs and ascertain the lack of cross contamination between neighboring out-of-focus neurons of different type (Figure 2A). D2 MSNs were not further analyzed. The same protocol was performed in the presence of either the $\mathrm{M}_{4}$-selective antagonist tropicamide $(1 \mu \mathrm{M}$, Figure $2 \mathrm{~B})$ or the $\mathrm{M}_{1}$-selective antagonist, VU0255035 (500 $\mathrm{nM}$, Figure 2C). Oxotremorine-induced cAMP inhibition was completely abolished in the presence of tropicamide (oxotremorine: $91 \pm 8 \%$ reduction, $\mathrm{n}=25, \mathrm{~N}=5$ vs oxotremorine + tropicamide: $2 \pm 3 \%, \mathrm{n}=20, \mathrm{~N}=5$; $\mathrm{p}$-value $<0.0001$ from unpaired $\mathrm{t}$ test) whereas VU0255035 had no significant effect on the oxotremorine-induced cAMP inhibition (oxotremorine: $91 \pm 8 \%$ reduction, $\mathrm{n}=25, \mathrm{~N}=5$ vs oxotremorine + VU0255035: $85 \pm 9 \%$, $\mathrm{n}=29, \mathrm{~N}=5 ; \mathrm{p}$-value $=0.29$ from unpaired $\mathrm{t}$ test $)$. Each condition was tested in 5 independent experiments (Figure 2D). Thus, the oxotremorine-induced inhibition of forskolin-induced 
steady state cAMP observed here is consistent with the involvement of mainly $\mathrm{M}_{4}$ receptors.

We then quantified the efficacy of the muscarinic receptor in reducing the steady state cAMP level elicited by forskolin. The previous protocol was repeated with different doses of oxotremorine, testing a single dose per brain slice. Each dose was tested in 5 independent experiments, with at least 25 cells per condition. The effect of oxotremorine was reversed by the application of the non-selective muscarinic antagonist, atropine $(2 \mu \mathrm{M})$, thus confirming on every experiment that the measured response was mediated by muscarinic receptors. This dose-response analysis provided an $\mathrm{EC}_{50}$ of $53 \pm 18 \mathrm{nM}$ and a maximal reduction of $87 \%$ (Figure 2E). These experiments show that muscarinic receptors exert a powerful inhibition on cAMP production in D1 MSNs.

\section{$M_{4}$ receptor has strong functional coupling to $D_{1}$-dependent $c A M P$ signaling}

$\mathrm{M}_{4}$ has been reported to inhibit $\mathrm{D}_{1}$-dependent cAMP signaling on striatal membranes (Olianas et al., 1996). However, $\mathrm{G}_{\text {olf }}$ that mediates $\mathrm{D}_{1}$-receptor signaling is pre-coupled with AC5 within a signaling complex (Xie et al., 2015), and this could affect the efficacy of the $\mathrm{M}_{4}$-dependent inhibition of adenylyl cyclases mediated by $\mathrm{G}_{\mathrm{i}}$. Thus, we measured whether $\mathrm{M}_{4}$ exerted the same inhibitory effect on the cAMP production induced by $\mathrm{D}_{1}$ receptors.

cAMP level was first increased by applying a low dose of SKF-81297 (50 nM). This dose was chosen to produce a near-maximal $\mathrm{D}_{1}$-dependent cAMP response without $\mathrm{D}_{1}$ desensitization. Oxotremorine was then added at the tested dose on this steady-state cAMP level (Figure 3A). A single dose was tested per brain slice, and each dose was tested at least 4 times, with 15-30 cells per dose. At a dose of $1 \mu \mathrm{M}$ and above, oxotremorine completely reversed the SKF-81297-induced increase in cAMP, returning the biosensor signal to baseline level. This indicates that the inhibitory effect mediated by muscarinic receptors fully overpowers $\mathrm{D}_{1}$-dependent cAMP production. Oxotremorine reduced $\mathrm{D}_{1}$-dependent steady state cAMP with an $\mathrm{EC}_{50}$ of $53 \pm 14 \mathrm{nM}$ (Figure $3 \mathrm{~B}$ ), similar to what was obtained when cAMP was increased with forskolin.

$\mathrm{D}_{1}$ receptors are activated by transient dopamine inputs resulting in transient cAMP signaling (Yagishita et al., 2014; Yapo et al., 2017). It has been hypothesized by computational modeling that background muscarinic receptor activity could blunt this transient cAMP signaling (Nair et al., 2015). Thus, we tested the effect of muscarinic receptor activation on dopamine-dependent transient cAMP signaling. Transient dopamine elevation was achieved using uncaging of caged-dopamine compound (NPEC-DA) with UV illumination. This results in the instantaneous and full photo-release of dopamine in the imaging volume, followed by an exponential decay dictated by diffusion of dopamine out of the slice (Yapo et al., 2017). In the presence of oxotremorine $(1 \mu \mathrm{M})$, a first dopamine uncaging (NPEC-DA, $3 \mu \mathrm{M}$ ) was performed, triggering a moderate cAMP response. After this first response recovered to baseline, atropine $(2 \mu \mathrm{M})$ was applied to suppress the muscarinic inhibition, and a second dopamine uncaging was performed, producing a larger cAMP response (Figure 3C). The recording was then continued with the application of the $\mathrm{A}_{2 \mathrm{~A}}$ agonist CGS-21680 $(1 \mu \mathrm{M})$ and the $\mathrm{D}_{1}$ agonist SKF-81297 $(100 \mathrm{nM})$, to differentiate D1 and D2 MSN sub-types, and with forskolin and IBMX, as described previously (Yapo et al., 2017).

The amplitude of the cAMP response to dopamine uncaging was lower in the presence 
of oxotremorine than the control response obtained when muscarinic receptors were blocked, while this second response was similar to the one obtained without blockers (Yapo et al., 2017). We then analyzed the dose-dependency of the oxotremorine effect. The same experiment was repeated with different test doses: a single dose was tested per brain slice; each dose was tested 5 times, with 20-34 cells per condition. Muscarinic receptor stimulation reduced the response amplitude down to $40 \pm 7 \%$ of the control response (Figure 3D), showing that muscarinic receptors can blunt the cAMP response produced by transient dopamine. The $\mathrm{EC}_{50}$ of this effect was $65 \pm 32 \mathrm{nM}$, similar to oxotremorine efficacy on the steady state cAMP level measured above. However, while the effect of oxotremorine was total on the steady-state $\mathrm{D}_{1}$ response, the response to transient dopamine obtained after uncaging was not completely abolished, even at high concentrations of oxotremorine (Figure 3D).

Together, our measurements show that muscarinic receptors exert a powerful inhibition on $\mathrm{D}_{1}$-receptor induced cAMP production in D1 MSNs. This experimental observation supports the hypothesis that acetylcholine level should drop simultaneously with dopamine release to allow for a positive cAMP response in D1 MSNs (Nair et al., 2015).

\section{High efficacy of acetylcholine for cAMP inhibition}

$\mathrm{M}_{4}$ receptor has a similar affinity for oxotremorine and acetylcholine (Jakubík et al., 1997) and we wanted to confirm whether a low concentration of acetylcholine could also control cAMP responses. The striatum contains high acetylcholinesterase activity (Hoover et al., 1978; Taylor \& Radić, 1994) and to prevent acetylcholine degradation while diffusing throughout the brain slice, the reversible acetylcholinesterase inhibitor neostigmine $(1 \mu \mathrm{M})$ was applied simultaneously. The steady-state experimental protocol with forskolin described in previous sections was used except that acetylcholine was used instead of oxotremorine: a steady state cAMP level was obtained with low forskolin $(250 \mathrm{nM})$, and acetylcholine (100 $\mathrm{nM})$ and neostigmine $(1 \mu \mathrm{M})$ were applied together, reverting cAMP to baseline level (Figure 4A). The extent of cAMP reduction produced by acetylcholine was similar as that produced by the maximally effective concentrations of oxotremorine (acetylcholine + neostigmine: 95 $\pm 5 \%$ reduction $v s 10 \mu \mathrm{M}$ oxotremorine: $84 \pm 13 \%$ reduction; $\mathrm{p}$-value $>0.1$ from unpaired $\mathrm{t}$ test).

The effect of acetylcholine on transient cAMP signals elicited by dopamine uncaging was also tested, using the same protocol as the one used in Figure 3C: a first dopamine uncaging was performed in the presence of acetylcholine $(100 \mathrm{nM})$ and neostigmine $(1 \mu \mathrm{M})$, and the second in presence of atropine $(2 \mu \mathrm{M})$ (Figure 4B). The amplitude of the cAMP peak produced by dopamine uncaging in the presence of acetylcholine and neostigmine was $38 \pm 6$ $\%$ of that obtained in the presence of atropine (Figure 4B). Again, the effect of $100 \mathrm{nM}$ acetylcholine was the same as the effect of muscarinic receptor stimulation with the maximally effective concentration of oxotremorine (amplitude of uncaging response: acetylcholine + neostigmine: $38 \pm 6 \% v s 10 \mu \mathrm{M}$ oxotremorine: $37 \pm 9 \%$; p-value $>0.8$ from unpaired $t$ test).

\section{Acetylcholine and $\mathrm{M}_{\mathbf{4}}$ modulators reverse hyperlocomotion in DAT-KO mice}

We then wanted to test whether the high efficacy of acetylcholine could counteract 
aberrant dopamine action in vivo. For this, we used DAT knockout mice, a well established model where chronic hyperdopaminergia induces spontaneous hyperlocomotion (Giros et al., 1996). We first assessed the effects of two procholinergic compounds used in everyday clinical practice to increase the levels of acetylcholine in the brain, the acetylcholinesterase inhibitors donepezil and tacrine. Administration of these drugs to DAT knockout mice strongly reduced their locomotor activity (Figure 5A, B; one-way ANOVA: for donepezil $\mathrm{F}(3,27)=13.6 ; \mathrm{p}<0.0001$; for tacrine $\mathrm{F}(3,17)=19.02 ; \mathrm{p}<0.0001$; Duncan's post-hoc test). Even though basal locomotor activity was much lower in the wild-type than in the DAT-KO, both compounds also reduced locomotor activity in WT mice, when administered at the highest dose (Figure 5C,D one-way ANOVA (for donepezil $\mathrm{F}(3,35)=3.05 ; \mathrm{p}=0.04$; for tacrine $\mathrm{F}(3,13)=3.77 ; \mathrm{p}=0.03)$ and Duncan's post-hoc). Subsequently, we targeted the $\mathrm{M}_{4}$ receptor using selective $\mathrm{M}_{4}$ positive allosteric modulators (Conn et al., 2009). The intraperitoneal injection of a brain-penetrant $\mathrm{M}_{4}$ modulator VU0152100 (Brady et al., 2008) in DAT knockout mice mimicked the effects of acetylcholinesterase inhibitors, reducing locomotor activity (Figure 5E; one-way ANOVA $F(2,12)=6.41 ; p=0.0127$; Duncan's post-hoc). Furthermore, intrastriatal injection of a non-permeant analogue, VU0010010 (Shirey et al., 2008), also efficiently reduced locomotor activity in the DAT knockout (Figure 5F; one wayANOVA $F(2,12)=10.75 ; p=0.00211$; Duncan's post-hoc). Altogether, these experiments show that enhancing the cholinergic tone reduces the functional effects of striatal hyperdopaminergia through $\mathrm{M}_{4}$ receptors, consistent with a strong inhibitory effect of $\mathrm{M}_{4}$ on dopamine signaling in vivo. 


\section{DISCUSSION}

A number of observations highlighted the role played by $\mathrm{M}_{4}$ muscarinic receptors in the regulation of basal ganglia function, and in MSNs in particular, such as the regulation of calcium currents or synaptic plasticity (Howe \& Surmeier, 1995; Shen et al., 2015). Paired recording or optogenetic stimulation showed that $\mathrm{M}_{4}$ receptors can mediate high-fidelity synaptic transmission, which efficiently controls the release of GABA by D1 MSNs (Mamaligas \& Ford, 2016). In silico modeling suggested that a pause in cholinergic activity is required to open the gate for the $\mathrm{D}_{1}$ signal, provided that the $\mathrm{M}_{4}$ receptor has enough sensitivity to the low level of acetylcholine, and that $\mathrm{G}_{\mathrm{i} / \mathrm{o}}$-mediated inhibition of adenylyl cyclase would be powerful enough to overcome the action of $\mathrm{D}_{1}$-stimulated $\mathrm{G}_{\text {olf }}$ (Nair et al., 2015). Although $\mathrm{M}_{4}$-mediated synaptic current had been described in great details, with synaptically-released acetylcholine being sufficient to activate a postsynaptic response (Mamaligas \& Ford, 2016), the $\mathrm{EC}_{50}$ and maximal efficacy of acetylcholine remained uncertain at the level of its physiological effector, the cAMP/PKA signaling pathway. Biosensor imaging provides a direct monitoring of changes in cAMP concentration and we used this approach to quantify the effect of $\mathrm{M}_{4}$ receptor activation in its native cellular environment. We report here that muscarinic receptors functionally present specifically on D1 MSNs exert a powerful negative control on the production of cAMP induced by $\mathrm{D}_{1}$ receptors, with an $\mathrm{EC}_{50}$ of acetylcholine below $100 \mathrm{nM}$. In vivo, a powerful negative control exerted by $\mathrm{M}_{4}$-selective PAMs on dopamine action reverses the hyperdopaminergic motor phenotype of DAT knock-out mice, and we suggest that this effect involves the powerful negative control exerted by muscarinic stimulation on cAMP in D1 MSNS.

Out of the five muscarinic receptors, $\mathrm{M}_{4}$ is the predominant form expressed selectively in D1 MSNs, while $\mathrm{M}_{1}$ receptor is expressed in most striatal neurons (Bernard et al., 1992; Hersch et al., 1994; Ince et al., 1997). The other receptors, although present at low level at the mRNA level in MSNs (Yan et al., 2001) seem to lead to little protein expression (Eglen, 2012). $\mathrm{M}_{2}$, the other muscarinic receptor negatively coupled to cAMP production, is expressed in cholinergic interneurons (Hersch et al., 1994; Zhao et al., 2016). In the striatum, the negative coupling of $\mathrm{M}_{4}$ to $\mathrm{cAMP}$ has already been reported by biochemical measurements on striatal brain slices, whereas $\mathrm{M}_{1}$ receptors, coupled by $\mathrm{Ga}_{\mathrm{q} / 11}$, were shown to trigger a modest increase in cAMP (Sánchez-Lemus \& Arias-Montaño, 2006; Sánchez et al., 2009). Furthermore, muscarinic stimulation reduced $D_{1}$-induced cAMP production, an effect that was shown to selectively require $\mathrm{M}_{4}$ receptors in D1 MSNS (Jeon et al., 2010). Out of $\mathrm{M}_{1}$ and $\mathrm{M}_{4}$ receptors present in D1 MSNs, several observations in our experiments indicate that it is indeed the $\mathrm{M}_{4}$ receptor which is the mediator of the negative control of cAMP signaling described here. First, muscarinic stimulation decreased cAMP, which is consistent with the already reported negative coupling of $\mathrm{M}_{4}$. In addition, tropicamide completely blocked this effect, while VU0255035 did not. While the selectivity of tropicamide is moderate (Lazareno \& Birdsall, 1993), VU0255035 has a 80 fold selectivity for $\mathrm{M}_{1}$ compared to $\mathrm{M}_{4}$ (Sheffler et al., 2009). The efficacy of tropicamide and lack of effect of VU0255035 again strongly suggests that $\mathrm{M}_{4}$ is responsible for the muscarinic effect described here. Moreover, if oxotremorine had an effect through $\mathrm{M}_{1}$ receptors and since $\mathrm{M}_{1}$ receptors are expressed by both D1 and D2 MSNs, we should have seen an effect of oxotremorine on the cAMP level in D2 MSNs, which was not the case (Figure 2). 
Oxotremorine and acetylcholine bind to the $\mathrm{M}_{4}$ receptor with an affinity of 6 and 30 $\mu \mathrm{M}$, respectively (Jakubík et al., 1997), while inhibition of adenylyl cyclase activity by acetylcholine in striatal membranes yielded numbers in the micromolar range (Olianas et al., 1996; Olianas \& Onali, 1999). In living striatal neurons, application of oxotremorine-M activated overexpressed GIRK2 channels with an $\mathrm{EC}_{50}$ of 200 to $400 \mathrm{nM}$ (Mamaligas \& Ford, 2016). In contrast, we found an $\mathrm{EC}_{50}$ of oxotremorine around $60 \mathrm{nM}$ on cAMP signaling, the predominant intracellular signal triggered by dopamine. The $\mathrm{EC}_{50}$ of acetylcholine is even lower than this value since $100 \mathrm{nM}$ acetylcholine produced a complete suppression of fskinduced cAMP production (Figure 4A), an effect that required at least $500 \mathrm{nM}$ oxotremorine (Figure $2 \mathrm{E}$ ). A precise measurement of acetylcholine $\mathrm{EC}_{50}$ would suppose to demonstrate a complete block of acetylcholinesterase activities, which could not be ascertained in our striatal brain slice preparation.

Our previous work with biosensor imaging in striatal brain slices also revealed $\mathrm{EC}_{50}$ values that differed from previously published values, in particular in the case of the $\mathrm{D}_{2}$ receptor (Yapo et al., 2017). Indeed, $\mathrm{M}_{4}$ and $\mathrm{D}_{2}$ receptors in MSNs have the same coupling mechanism and may be similarly affected by pre-coupling to the $\mathrm{G}_{\mathrm{i} / \mathrm{o}}$ protein (Bünemann $e t$ al., 2003). A number of other parameters such as expression level in heterologous systems can affect such measurements and have been thoroughly reviewed (Hulme \& Trevethick, 2010). This emphasizes the importance of performing such measurements with receptors in their native environment.

Such in situ measurement thus shows that a concentration of few tens of nanomolar of acetylcholine could be sufficient to activate $\mathrm{M}_{4}$ receptors. Our previous computational modeling study highlighted the consequences of $\mathrm{M}_{4}$ receptor activation, which could lead to the suppression of the striatal response to phasic dopamine through $\mathrm{D}_{1}$-dependent cAMP signaling. Acetylcholine level would determine whether the dopamine signal is passed on through the cAMP/PKA signaling pathway. The transduction of a dopamine signal into an increase in cAMP in D1 MSNs would thus require a pause in cholinergic activity, to lower the tonic level of acetylcholine and allow for dopamine to elicit a positive cAMP response (Nair et al., 2015).

However, the actual shape of striatal acetylcholine signal sensed by $\mathrm{M}_{4}$ receptors in D1 MSNs is not clear, in particular whether acetylcholine exerts its action by a tonic "basal" level, or through precisely timed synaptic release. Indeed, experimental measurement of physiological acetylcholine levels is technically challenging. Microdialysis measurements in vivo indicate a nanomolar range (Rada et al., 2010; Farrar et al., 2011), possibly representing the spatially and temporally averaged acetylcholine in the striatum. However, such measurement can significantly underestimate the actual level, as highlighted by electrochemical measurements (Mattinson et al., 2011). Electrophysiological measurements in brain slice preparations using GIRK2 channels in D1 MSNs provide an optimal temporal resolution and have shown that tonic firing of cholinergic neurons produce discrete metabotropic synaptic currents with no sustained response between these synaptic events (Mamaligas \& Ford, 2016). However, acetylcholine release is likely to be higher in vivo than in slices that lack excitatory drive and suffer disruption of the broad axonal arborization. In addition, the readout with GIRK channels may not reflect what happens at the level of cAMP since oxotremorine-M EC $\mathrm{C}_{50}$ measured with GIRK currents was $\sim 5$ fold higher (200-400 nM) than our readout at the level of cAMP. This leaves open the possibility that low tonic levels of 
acetylcholine between synaptic events might affect cAMP through $\mathrm{G}_{\alpha \mathrm{i}}$ while no effect can be seen on $\mathrm{G}_{\beta \gamma}$-coupled potassium currents. Indeed, different levels of neurotransmitter selectively recruit different branches of downstream signaling cascades depending on the coupling mechanism, an effect that was already observed with the $\mathrm{D}_{2}$ receptors in the D2 MSNs, analogous to $\mathrm{M}_{4}$ in D1 MSNs (Nair et al., 2015; Yapo et al., 2017). Acetylcholine levels will also fluctuate in vivo depending on the behavioral context (Benhamou et al., 2014). Pauses in the activity of cholinergic neurons occur in response to reward or salient stimulus during reinforcement learning, though their physiological relevance have not been fully understood (Morris et al., 2004; Aosaki et al., 2010; Schulz et al., 2011). Thus, the coincidence detection between a cholinergic pause and reward-related dopamine transient could be viewed as the integration of stimulus saliency and reward information, a possible way to ensure that dopamine-dependent learning mechanisms could be recruited only in the presence of high-saliency environmental cues.

This powerful negative control of $\mathrm{M}_{4}$ receptor on the $\mathrm{D}_{1}$-mediated cAMP response gives a mechanistic substrate for a number of pathophysiological observations concerning the dopamine / acetylcholine balance in the striatum. A number of reports showed the importance of muscarinic receptors in neuropsychiatric disorders such as Parkinson's disease, schizophrenia and drug addiction, as previously reviewed (Dencker et al., 2012a). Indeed, in a clinical setting, $\mathrm{M}_{4}$-mediated inhibition might be beneficial to oppose excessive dopamine signaling such as that produced by levodopa treatment: $\mathrm{M}_{4}$-selective PAMs attenuated LDOPA induced dyskinetic behaviors (Shen et al., 2015). Accordingly, lack of $\mathrm{M}_{4}$ receptor in the knockout is associated with highly increased locomotor activity, a measure of striatal hyperdopaminergia (Gomeza et al., 1999) and hypersensitivity to dopamine agonists (Tzavara et al., 2004). Along this line, $\mathrm{M}_{4}$-selective PAMs were also shown to reverse some features of increased dopamine in animal models of acute psychotomimetic administration, suggesting a possible antipsychotic efficacy (Brady et al., 2008; Byun et al., 2014; Chan et al., 2008), while selective knockout of $\mathrm{M}_{4}$ receptors in D1 MSNs was sufficient to suppress the antipsychotic-like effect of the $\mathrm{M}_{1} / \mathrm{M}_{4}$ agonist xanomeline (Dencker et al., 2011), again highlighting the critical importance of the balance between $\mathrm{D}_{1}$ and $\mathrm{M}_{4}$ receptors. Coadministration of the $\mathrm{M}_{4}$-selective PAMs VU0152100 reduced the behavioral effects of cocaine, an effect that again involved D1 MSNs since it was lost in D1-selective $\mathrm{M}_{4}$ knockout (Dencker et al., 2012b). This suggests a therapeutic value for PAMs in another pathological condition, the response to addictive drugs which involves a widespread release of dopamine and activation of the cAMP pathway in D1 MSNs.

All the above models involve acute administration of dopaminergic/psychotomimetic compounds. Here, we explored the ability of increased acetylcholine neurotransmission via $\mathrm{M}_{4}$ receptors to counteract the effects of chronic hyperdopaminergia. In DAT KO mice, a five-fold increase in extracellular dopamine in the brain is associated with hyperactivity. In contrast to antipsychotics, this hyperactivity, paradoxically, is inhibited by psychostimulants like amphetamine and methylphenidate (Gainetdinov \& Caron, 2003) and attention deficit hyperactivity disorder (ADHD) compounds such as reboxetine (Barth et al., 2013), thereby providing a simple model in which the effects of ADHD pharmacological agents can be assessed. In this context, we further show that increasing acetylcholine with acetylcholinesterase inhibitors donepezil and tacrine reverses the hyperlocomotion that is characteristic of this mouse line. This effect involves $\mathrm{M}_{4}$ receptors as it is reproduced by 
systemic administration of the $\mathrm{M}_{4}$ PAM VU0152100. In addition, targeting $\mathrm{M}_{4}$ receptors locally in the striatum is sufficient to reduce hyperlocomotion, thus linking high affinity $\mathrm{M}_{4}-$ dependent regulation of dopamine signaling at the MSN cellular level with a therapeutically relevant behavioral readout.

The present findings show that the $\mathrm{M}_{4}$ receptor exerts a powerful negative control on the integration of dopamine signals in D1 MSNs. Enhancing $\mathrm{M}_{4}$-mediated downregulation of dopamine responsiveness in the striatum may constitute a novel therapeutic strategy in the hyperdopaminergia associated with dysregulated locomotor activity relevant to different disorders, for instance in L-Dopa induced dyskinesia or in ADHD.

\section{ACKNOWLEDGEMENTS}

This work was supported in part by the Investissements d'Avenir program managed by the ANR under reference ANR-11-IDEX-0004-02. JKH received fundings from the European Horizon 2020 Framework Programme under grant agreement n॰785907 (Human Brain Project SGA2), the Swedish Research Council and Swedish e-Science Research Center. AGN received a funding from EuroSPIN, an Erasmus Mundus Joint Doctoral program. VG was supported by a FondaMental Servier Graduate award. ETT would like to acknowledge a NARSAD support for early stages of this study. 


\section{REFERENCES}

Aoki, S., Liu, A.W., Zucca, A., Zucca, S. \& Wickens, J.R., 2015. Role of Striatal Cholinergic Interneurons in Set-Shifting in the Rat. J Neurosci 35, 9424-9431.

Aosaki, T., Kimura, M. \& Graybiel, A.M., 1995. Temporal and spatial characteristics of tonically active neurons of the primate's striatum. J Neurophysiol 73, 1234-1252.

Aosaki, T., Miura, M., Suzuki, T., Nishimura, K. \& Masuda, M., 2010. Acetylcholine-dopamine balance hypothesis in the striatum: an update. Geriatr Gerontol Int 10 Suppl 1, S148-57.

Aosaki, T., Tsubokawa, H., Ishida, A., Watanabe, K., Graybiel, A.M. \& Kimura, M., 1994. Responses of tonically active neurons in the primate's striatum undergo systematic changes during behavioral sensorimotor conditioning. J Neurosci 14, 3969-3984.

Apazoglou, K., Farley, S., Gorgievski, V., Belzeaux, R., Lopez, J.P., Grenier, J., Ibrahim, E.C., El Khoury, M.-A., Tse, Y.C., Mongredien, R., Barbé, A., de Macedo, C.E.A., Jaworski, W., Bochereau, A., Orrico, A., Isingrini, E., Guinaudie, C., Mikasova, L., Louis, F., Gautron, S., Groc, L., Massaad, C., Yildirim, F., Vialou, V., Dumas, S., Marti, F., Mechawar, N., Morice, E., Wong, T.P., Caboche, J., Turecki, G., Giros, B. \& Tzavara, E.T., 2018. Antidepressive effects of targeting ELK-1 signal transduction. Nature Medicine

Barth, V., Need, A.B., Tzavara, E.T., Giros, B., Overshiner, C., Gleason, S.D., Wade, M., Johansson, A.M., Perry, K., Nomikos, G.G. \& Witkin, J.M., 2013. In vivo occupancy of dopamine D3 receptors by antagonists produces neurochemical and behavioral effects of potential relevance to attention-deficit-hyperactivity disorder. J Pharmacol Exp Ther 344, 501-510.

Benhamou, L., Kehat, O. \& Cohen, D., 2014. Firing pattern characteristics of tonically active neurons in rat striatum: context dependent or species divergent. J Neurosci 34, 2299-2304.

Bernard, V., Normand, E. \& Bloch, B., 1992. Phenotypical characterization of the rat striatal neurons expressing muscarinic receptor genes. J Neurosci 12, 3591-3600.

Bolam, J.P., Wainer, B.H. \& Smith, A.D., 1984. Characterization of cholinergic neurons in the rat neostriatum. A combination of choline acetyltransferase immunocytochemistry, Golgiimpregnation and electron microscopy. Neuroscience 12,711-718.

Brady, A.E., Jones, C.K., Bridges, T.M., Kennedy, J.P., Thompson, A.D., Heiman, J.U., Breininger, M.L., Gentry, P.R., Yin, H., Jadhav, S.B., Shirey, J.K., Conn, P.J. \& Lindsley, C.W., 2008. Centrally active allosteric potentiators of the M4 muscarinic acetylcholine receptor reverse amphetamine-induced hyperlocomotor activity in rats. J Pharmacol Exp Ther 327, 941-953.

Bünemann, M., Frank, M. \& Lohse, M.J., 2003. Gi protein activation in intact cells involves subunit rearrangement rather than dissociation. Proc Natl Acad Sci U S A 100, 16077-16082.

Byun, N.E., Grannan, M., Bubser, M., Barry, R.L., Thompson, A., Rosanelli, J., Gowrishankar, R., Kelm, N.D., Damon, S., Bridges, T.M., Melancon, B.J., Tarr, J.C., Brogan, J.T., Avison, M.J., Deutch, A.Y., Wess, J., Wood, M.R., Lindsley, C.W., Gore, J.C., Conn, P.J. \& Jones, C.K., 2014. Antipsychotic drug-like effects of the selective M4 muscarinic acetylcholine receptor positive allosteric modulator VU0152100. Neuropsychopharmacology 39, 1578-1593.

Calabresi, P., Picconi, B., Parnetti, L. \& Di Filippo, M., 2006. A convergent model for cognitive dysfunctions in Parkinson's disease: the critical dopamine-acetylcholine synaptic balance. Lancet Neurol 5, 974-983.

Chan, W.Y., McKinzie, D.L., Bose, S., Mitchell, S.N., Witkin, J.M., Thompson, R.C., Christopoulos, A., Lazareno, S., Birdsall, N.J., Bymaster, F.P. \& Felder, C.C., 2008. Allosteric modulation of the muscarinic M4 receptor as an approach to treating schizophrenia. Proc Natl Acad Sci U S A 105, 10978-10983.

Conn, P.J., Jones, C.K. \& Lindsley, C.W., 2009. Subtype-selective allosteric modulators of muscarinic receptors for the treatment of CNS disorders. Trends Pharmacol Sci 30, 148-155.

Contant, C., Umbriaco, D., Garcia, S., Watkins, K.C. \& Descarries, L., 1996. Ultrastructural characterization of the acetylcholine innervation in adult rat neostriatum. Neuroscience 71, 937947.

Cragg, S.J., 2006. Meaningful silences: how dopamine listens to the ACh pause. Trends Neurosci 29, $125-131$. 
Dencker, D., Thomsen, M., Wörtwein, G., Weikop, P., Cui, Y., Jeon, J., Wess, J. \& Fink-Jensen, A., 2012a. Muscarinic Acetylcholine Receptor Subtypes as Potential Drug Targets for the Treatment of Schizophrenia, Drug Abuse and Parkinson's Disease. ACS Chem Neurosci 3, 80-89.

Dencker, D., Weikop, P., Sørensen, G., Woldbye, D.P., Wörtwein, G., Wess, J. \& Fink-Jensen, A., 2012b. An allosteric enhancer of $\mathrm{M}_{4}$ muscarinic acetylcholine receptor function inhibits behavioral and neurochemical effects of cocaine. Psychopharmacology (Berl) 224, 277-287.

Dencker, D., Wörtwein, G., Weikop, P., Jeon, J., Thomsen, M., Sager, T.N., Mørk, A., Woldbye, D.P., Wess, J. \& Fink-Jensen, A., 2011. Involvement of a subpopulation of neuronal M4 muscarinic acetylcholine receptors in the antipsychotic-like effects of the M1/M4 preferring muscarinic receptor agonist xanomeline. J Neurosci 31, 5905-5908.

Eglen, R.M., 2012. Overview of muscarinic receptor subtypes. Handb Exp Pharmacol 3-28.

Ehrengruber, M.U., Lundstrom, K., Schweitzer, C., Heuss, C., Schlesinger, S. \& Gähwiler, B.H., 1999. Recombinant Semliki Forest virus and Sindbis virus efficiently infect neurons in hippocampal slice cultures. Proc Natl Acad Sci U S A 96, 7041-7046.

Farrar, A.M., Callahan, J.W. \& Abercrombie, E.D., 2011. Reduced striatal acetylcholine efflux in the R6/2 mouse model of Huntington's disease: an examination of the role of altered inhibitory and excitatory mechanisms. Exp Neurol 232, 119-125.

Gainetdinov, R.R. \& Caron, M.G., 2003. Monoamine transporters: from genes to behavior. Annu Rev Pharmacol Toxicol 43, 261-284.

Giros, B., Jaber, M., Jones, S.R., Wightman, R.M. \& Caron, M.G., 1996. Hyperlocomotion and indifference to cocaine and amphetamine in mice lacking the dopamine transporter. Nature 379 , $606-612$.

Gomeza, J., Zhang, L., Kostenis, E., Felder, C., Bymaster, F., Brodkin, J., Shannon, H., Xia, B., Deng, C. \& Wess, J., 1999. Enhancement of D1 dopamine receptor-mediated locomotor stimulation in M(4) muscarinic acetylcholine receptor knockout mice. Proc Natl Acad Sci U S A 96, 1048310488.

Hersch, S.M., Gutekunst, C.A., Rees, H.D., Heilman, C.J. \& Levey, A.I., 1994. Distribution of m1-m4 muscarinic receptor proteins in the rat striatum: light and electron microscopic immunocytochemistry using subtype-specific antibodies. J Neurosci 14, 3351-3363.

Hoebel, B.G., Avena, N.M. \& Rada, P., 2007. Accumbens dopamine-acetylcholine balance in approach and avoidance. Curr Opin Pharmacol 7, 617-627.

Hoover, D.B., Muth, E.A. \& Jacobowitz, D.M., 1978. A mapping of the distribution of acetycholine, choline acetyltransferase and acetylcholinesterase in discrete areas of rat brain. Brain Res 153, 295-306.

Howe, A.R. \& Surmeier, D.J., 1995. Muscarinic receptors modulate N-, P-, and L-type Ca2+ currents in rat striatal neurons through parallel pathways. J Neurosci 15, 458-469.

Hulme, E.C. \& Trevethick, M.A., 2010. Ligand binding assays at equilibrium: validation and interpretation. Br J Pharmacol 161, 1219-1237.

Ince, E., Ciliax, B.J. \& Levey, A.I., 1997. Differential expression of D1 and D2 dopamine and m4 muscarinic acetylcholine receptor proteins in identified striatonigral neurons. Synapse 27, 357366.

Jakubík, J., Bacáková, L., El-Fakahany, E.E. \& Tucek, S., 1997. Positive cooperativity of acetylcholine and other agonists with allosteric ligands on muscarinic acetylcholine receptors. Mol Pharmacol 52, 172-179.

Jeon, J., Dencker, D., Wortwein, G., Woldbye, D.P., Cui, Y., Davis, A.A., Levey, A.I., Schutz, G., Sager, T.N., Mork, A., Li, C., Deng, C.X., Fink-Jensen, A. \& Wess, J., 2010. A subpopulation of neuronal M4 muscarinic acetylcholine receptors plays a critical role in modulating dopaminedependent behaviors. J Neurosci 30, 2396-2405.

Lazareno, S. \& Birdsall, N.J., 1993. Pharmacological characterization of acetylcholine-stimulated [35S]-GTP gamma $\mathrm{S}$ binding mediated by human muscarinic $\mathrm{m} 1-\mathrm{m} 4$ receptors: antagonist studies. Br J Pharmacol 109, 1120-1127.

Lester, D.B., Rogers, T.D. \& Blaha, C.D., 2010. Acetylcholine-dopamine interactions in the pathophysiology and treatment of CNS disorders. CNS Neurosci Ther 16, 137-162. 
Mamaligas, A.A. \& Ford, C.P., 2016. Spontaneous Synaptic Activation of Muscarinic Receptors by Striatal Cholinergic Neuron Firing. Neuron 91, 574-586.

Mattinson, C.E., Burmeister, J.J., Quintero, J.E., Pomerleau, F., Huettl, P. \& Gerhardt, G.A., 2011. Tonic and phasic release of glutamate and acetylcholine neurotransmission in sub-regions of the rat prefrontal cortex using enzyme-based microelectrode arrays. J Neurosci Methods 202, 199208.

Maurice, N., Liberge, M., Jaouen, F., Ztaou, S., Hanini, M., Camon, J., Deisseroth, K., Amalric, M., Kerkerian-Le Goff, L. \& Beurrier, C., 2015. Striatal Cholinergic Interneurons Control Motor Behavior and Basal Ganglia Function in Experimental Parkinsonism. Cell Rep 13, 657-666.

Morris, G., Arkadir, D., Nevet, A., Vaadia, E. \& Bergman, H., 2004. Coincident but distinct messages of midbrain dopamine and striatal tonically active neurons. Neuron 43, 133-143.

Nair, A.G., Gutierrez-Arenas, O., Eriksson, O., Vincent, P. \& Hellgren-Kotaleski, J., 2015. Sensing Positive versus Negative Reward Signals through Adenylyl Cyclase-Coupled GPCRs in Direct and Indirect Pathway Striatal Medium Spiny Neurons. J Neurosci 35, 14017-14030.

Nguyen, Q.T., Tsai, P.S. \& Kleinfeld, D., 2006. MPScope: a versatile software suite for multiphoton microscopy. J Neurosci Methods 156, 351-359.

Olianas, M.C., Adem, A., Karlsson, E. \& Onali, P., 1996. Rat striatal muscarinic receptors coupled to the inhibition of adenylyl cyclase activity: potent block by the selective $\mathrm{m} 4$ ligand muscarinic toxin 3 (MT3). Br J Pharmacol 118, 283-288.

Olianas, M.C. \& Onali, P., 1999. PD 102807, a novel muscarinic M4 receptor antagonist, discriminates between striatal and cortical muscarinic receptors coupled to cyclic AMP. Life Sci $65,2233-2240$.

Perez-Lloret, S. \& Barrantes, F.J., 2016. Deficits in cholinergic neurotransmission and their clinical correlates in Parkinson's disease. NPJ Parkinsons Dis 2, 16001.

Polito, M., Klarenbeek, J., Jalink, K., Paupardin-Tritsch, D., Vincent, P. \& Castro, L.R., 2013. The NO/cGMP pathway inhibits transient cAMP signals through the activation of PDE2 in striatal neurons. Front Cell Neurosci 7, 211.

Polito, M., Vincent, P. \& Guiot, E. (2014). Biosensor imaging in brain slice preparations. In 1071 ed. Zhang, J., pp. 175-194. Humana Press,

Rada, P., Barson, J.R., Leibowitz, S.F. \& Hoebel, B.G., 2010. Opioids in the hypothalamus control dopamine and acetylcholine levels in the nucleus accumbens. Brain Res 1312, 1-9.

Sánchez-Lemus, E. \& Arias-Montaño, J.A., 2006. M1 muscarinic receptors contribute to, whereas M4 receptors inhibit, dopamine D1 receptor-induced [3H]-cyclic AMP accumulation in rat striatal slices. Neurochem Res 31, 555-561.

Sánchez, G., Colettis, N., Vázquez, P., Cerveñansky, C., Aguirre, A., Quillfeldt, J.A., Jerusalinsky, D. \& Kornisiuk, E., 2009. Muscarinic inhibition of hippocampal and striatal adenylyl cyclase is mainly due to the M(4) receptor. Neurochem Res 34, 1363-1371.

Schulz, J.M., Oswald, M.J. \& Reynolds, J.N., 2011. Visual-induced excitation leads to firing pauses in striatal cholinergic interneurons. J Neurosci 31, 11133-11143.

Sheffler, D.J., Williams, R., Bridges, T.M., Xiang, Z., Kane, A.S., Byun, N.E., Jadhav, S., Mock, M.M., Zheng, F., Lewis, L.M., Jones, C.K., Niswender, C.M., Weaver, C.D., Lindsley, C.W. \& Conn, P.J., 2009. A novel selective muscarinic acetylcholine receptor subtype 1 antagonist reduces seizures without impairing hippocampus-dependent learning. Mol Pharmacol 76, 356368.

Shen, W., Plotkin, J.L., Francardo, V., Ko, W.K., Xie, Z., Li, Q., Fieblinger, T., Wess, J., Neubig, R.R., Lindsley, C.W., Conn, P.J., Greengard, P., Bezard, E., Cenci, M.A. \& Surmeier, D.J., 2015. M4 Muscarinic Receptor Signaling Ameliorates Striatal Plasticity Deficits in Models of L-DOPAInduced Dyskinesia. Neuron 88, 762-773.

Shirey, J.K., Xiang, Z., Orton, D., Brady, A.E., Johnson, K.A., Williams, R., Ayala, J.E., Rodriguez, A.L., Wess, J., Weaver, D., Niswender, C.M. \& Conn, P.J., 2008. An allosteric potentiator of M4 mAChR modulates hippocampal synaptic transmission. Nat Chem Biol 4, 42-50.

Taylor, P. \& Radić, Z., 1994. The cholinesterases: from genes to proteins. Annu Rev Pharmacol Toxicol 34, 281-320. 
Tzavara, E.T., Bymaster, F.P., Davis, R.J., Wade, M.R., Perry, K.W., Wess, J., McKinzie, D.L., Felder, C. \& Nomikos, G.G., 2004. M4 muscarinic receptors regulate the dynamics of cholinergic and dopaminergic neurotransmission: relevance to the pathophysiology and treatment of related CNS pathologies. FASEB J 18, 1410-1412.

Tzavara, E.T., Li, D.L., Moutsimilli, L., Bisogno, T., Di Marzo, V., Phebus, L.A., Nomikos, G.G. \& Giros, B., 2006. Endocannabinoids activate transient receptor potential vanilloid 1 receptors to reduce hyperdopaminergia-related hyperactivity: therapeutic implications. Biol Psychiatry 59, 508-515.

Xie, K., Masuho, I., Shih, C.C., Cao, Y., Sasaki, K., Lai, C.W., Han, P.L., Ueda, H., Dessauer, C.W., Ehrlich, M.E., Xu, B., Willardson, B.M. \& Martemyanov, K.A., 2015. Stable G protein-effector complexes in striatal neurons: mechanism of assembly and role in neurotransmitter signaling. Elife 4,

Yagishita, S., Hayashi-Takagi, A., Ellis-Davies, G.C., Urakubo, H., Ishii, S. \& Kasai, H., 2014. A critical time window for dopamine actions on the structural plasticity of dendritic spines. Science 345, 1616-1620.

Yan, Z., Flores-Hernandez, J. \& Surmeier, D.J., 2001. Coordinated expression of muscarinic receptor messenger RNAs in striatal medium spiny neurons. Neuroscience 103, 1017-1024.

Yapo, C., Nair, A.G., Clement, L., Castro, L.R., Hellgren Kotaleski, J. \& Vincent, P., 2017. Detection of phasic dopamine by D1 and D2 striatal medium spiny neurons. J Physiol 595, 7451-7475.

Zhao, Z., Zhang, K., Liu, X., Yan, H., Ma, X., Zhang, S., Zheng, J., Wang, L. \& Wei, X., 2016. Involvement of HCN Channel in Muscarinic Inhibitory Action on Tonic Firing of Dorsolateral Striatal Cholinergic Interneurons. Front Cell Neurosci 10, 71. 


\section{A}
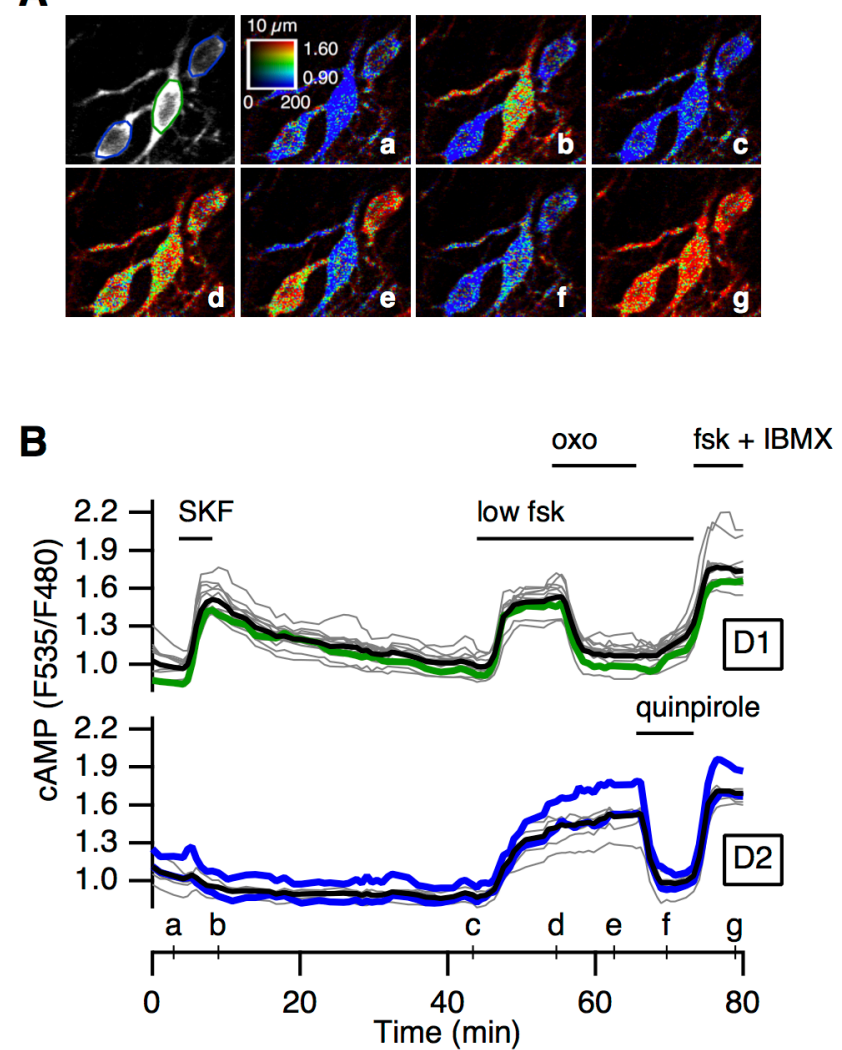

\section{Figure 1: A negative cAMP response mediated by muscarinic receptors is present selectively in D1 neurons.}

(A) A part of the image stack showing one D1 and two D2 MSNs (out of 21 neurons) in a brain slice expressing the cAMP biosensor Epac-S ${ }^{\mathrm{H} 150}$, imaged with two-photon microscopy: raw fluorescence of the donor is displayed in grey and donor/acceptor fluorescence ratio is displayed in pseudo-colour. Images (a-g) show the ratio corresponding to the time points indicated on the graph below. (B) Each trace indicates the emission ratio measured on the cell body of individual neurons. Traces are grouped on the basis of their similar response pattern. Thick colored traces correspond to the 3 cells illustrated in (A). Black traces represent the average response. Bath application of SKF-81297 (SKF, $100 \mathrm{nM}$ ) revealed MSNs which express D1-like receptors. A low dose of forskolin (low fsk, $0.5 \mu \mathrm{M}$ ) increased cAMP in all MSNs. Addition of the muscarinic agonist oxotremorine $(1 \mu \mathrm{M})$ decreased cAMP in the neurons which also responded to the $\mathrm{D}_{1}$ agonist. The neurons that did not respond to oxotremorine responded to the $\mathrm{D}_{2}$ agonist quinpirole $(1 \mu \mathrm{M})$ and therefore were D2 MSNs. The final application of forskolin (to activate adenylyl cyclases, fsk, $13 \mu \mathrm{M}$ ) and IBMX (to inhibit phosphodiesterases, $200 \mu \mathrm{M}$ ) showed the maximal ratio response for each neuron. The calibration square indicates from left to right increasing intensity levels, from bottom to top increasing ratio values, i.e. increasing intracellular cAMP concentration. The size of the square is $10 \mu \mathrm{m}$. 
A

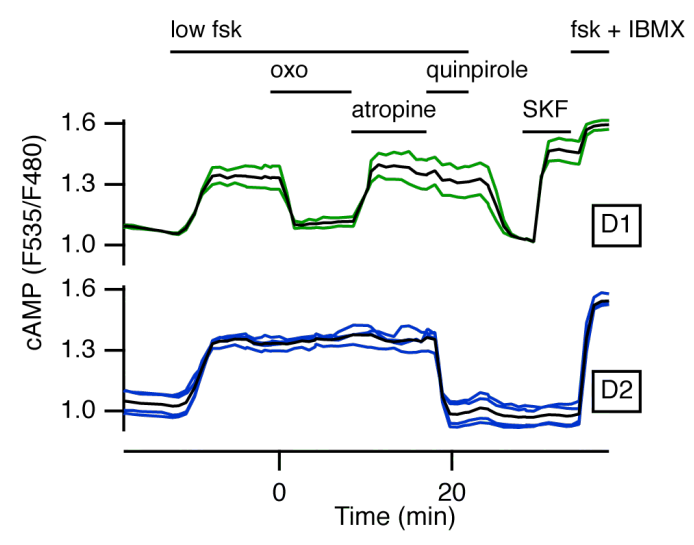

C

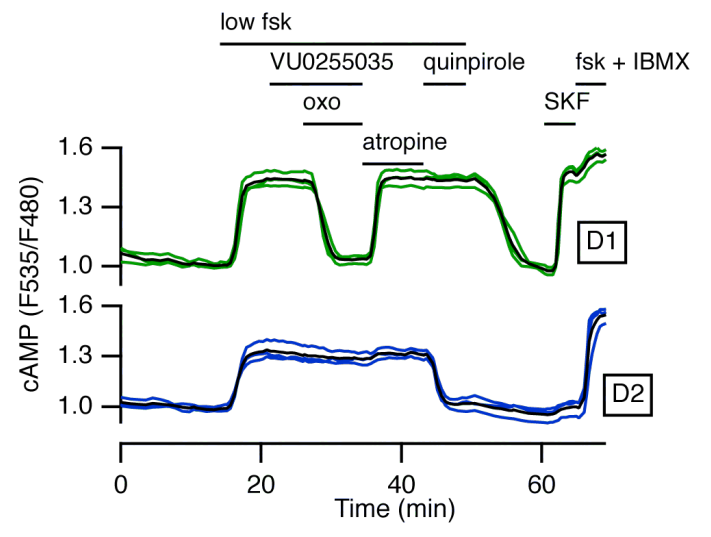

B

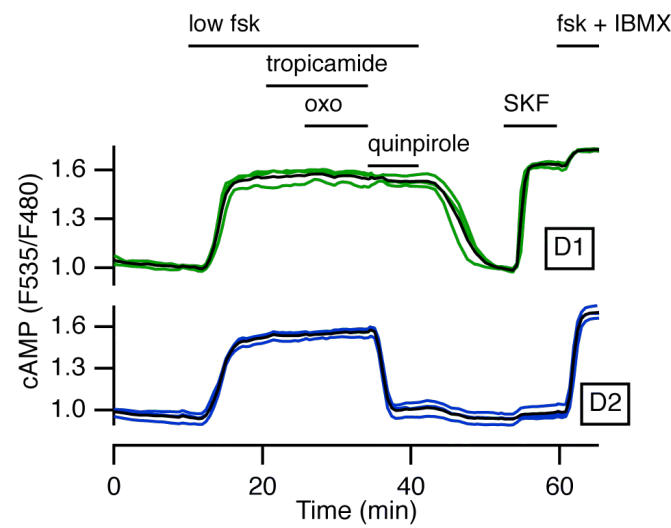

D

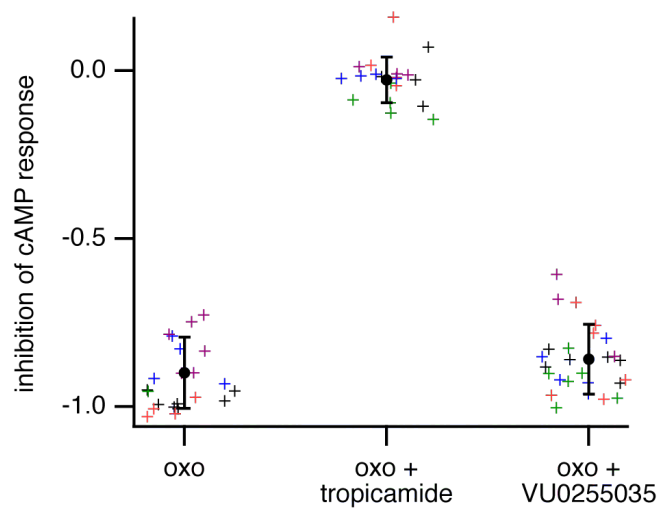

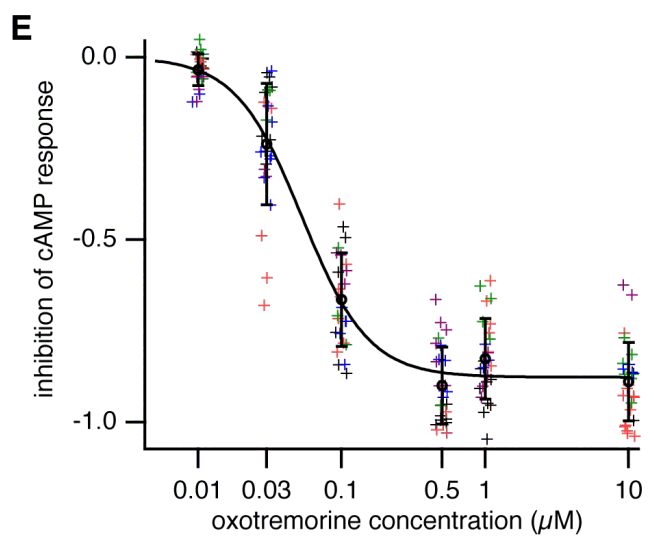

\section{FIGURE 2: M4 MUSCARINIC RECEPTORS DOSE-DEPENDENTLY DECREASES CAMP PRODUCTION IN DI MSNS.}

Striatal brain slice expressing the cAMP biosensor Epac-S ${ }^{\mathrm{H} 150}$ were imaged with widefield microscopy. For all experiments, a low concentration of forskolin (low fsk, $250 \mathrm{nM}$ ) was applied to increase cAMP production. D1 MSNs (green traces) were revealed by their positive cAMP response to $100 \mathrm{nM}$ SKF-81297 (SKF). D2 MSNs (blue traces) were revealed by their negative cAMP response to $1 \mu \mathrm{M}$ quinpirole. (A) Oxotremorine (oxo, $0.5 \mu \mathrm{M}$ ) decreased cAMP, an effect which was blocked by $2 \mu \mathrm{M}$ of the non-selective muscarinic antagonist atropine. (B) Oxotremorine had no effect in the presence of the M4 antagonist 
tropicamide $(1 \mu \mathrm{M})$. (C) The M1-selective antagonist VU0255035 $(0.5 \mu \mathrm{M})$ did not prevent the negative response to oxo. (D) Summary of the oxo effect, and in the presence of tropicamide or VU0255035. (E) The protocol illustrated in (A) was repeated with different oxo concentrations. The average was fitted to a Hill equation with an $\mathrm{EC}_{50}$ of $53 \mathrm{nM} \pm 18 \mathrm{nM}$, a maximal reduction of $88 \% \pm 7 \%$ and a Hill coefficient of 1.9. (D-E) The same experiment was repeated 5 times for each condition. Each symbol $(+)$ represents the measurement performed on a single D1 MSN, displayed in a same color for a same experiment. 

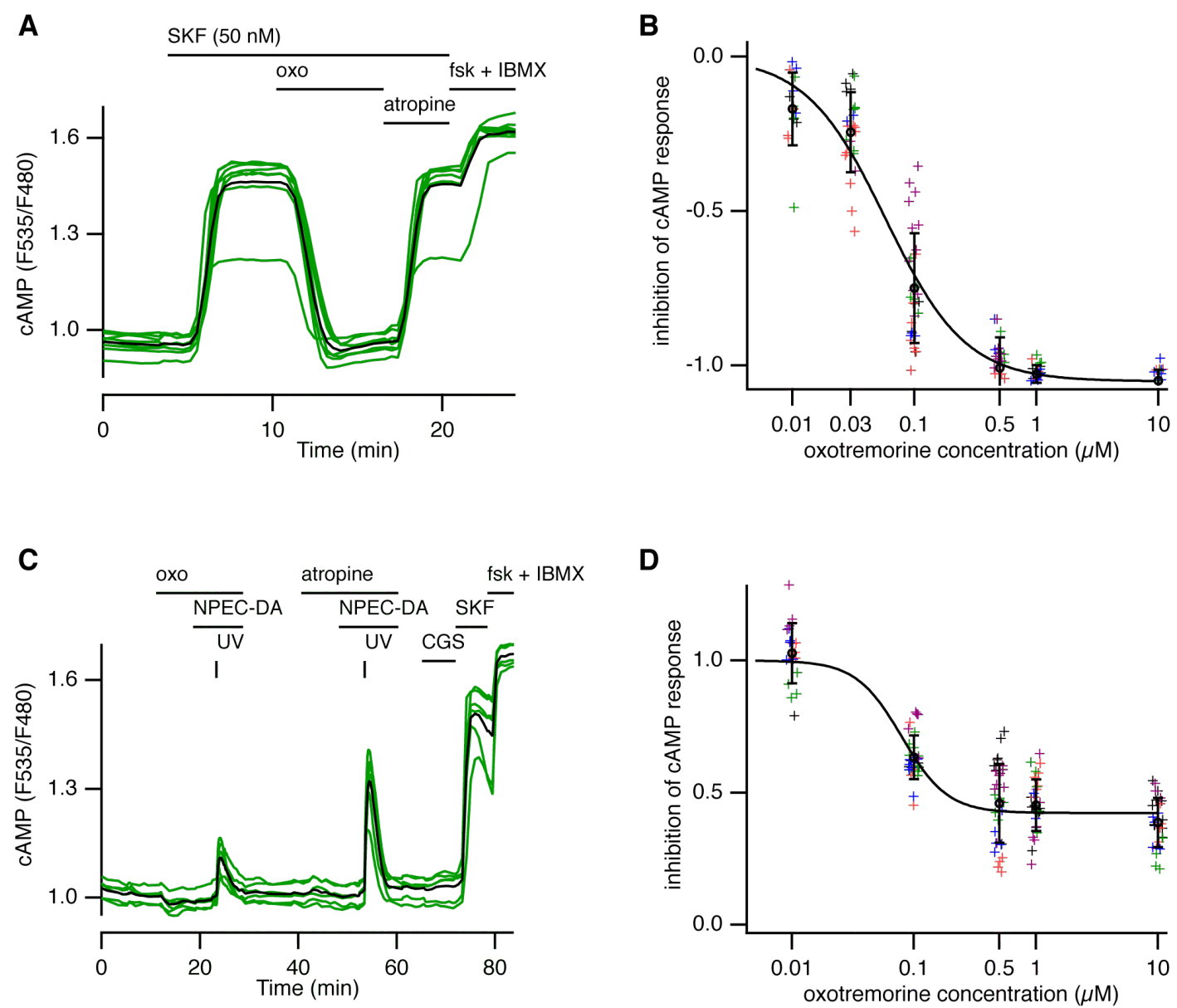

\section{FIGURE 3: ACTIVATION OF MUSCARINIC RECEPTORS WITH OXOTREMORINE INHIBITS DI-INDUCED CAMP PRODUCTION.}

Striatal brain slice expressing the cAMP biosensor Epac-S ${ }^{\mathrm{H} 150}$ were imaged with widefield microscopy. (A) A low concentration of SKF (50 nM) increased cAMP in D1 MSNs. Application of $1 \mu \mathrm{M}$ oxotremorine (oxo) decreased cAMP, and this effect was reversed with atropine $(2 \mu \mathrm{M})$. (B) The same protocol was repeated with different oxotremorine concentrations. The average was fitted to a Hill equation with an $\mathrm{EC}_{50}$ of $58 \mathrm{nM} \pm 20 \mathrm{nM}$, a maximal reduction of $105 \% \pm 3 \%$ and a Hill coefficient of 1.3. (C) $1 \mu \mathrm{M}$ oxotremorine (oxo) reduced the response to dopamine. $3 \mu \mathrm{M}$ of caged dopamine (NPEC-DA) was applied in the bath and the dopamine was released by a flash of UV light. A second uncaging protocol was performed in the presence of $2 \mu \mathrm{M}$ atropine. Lack of response to CGS and positive response to SKF confirmed the D1 identity of the recorded neurons. (D) The same protocol was repeated with different doses of oxo, measuring the ratio of the second peak divided by the first peak. The average was fitted to a Hill equation with an $\mathrm{EC}_{50}$ of $79.4 \mathrm{nM} \pm 67 \mathrm{nM}$, a maximal reduction of $42 \% \pm 7 \%$ and a Hill coefficient of 2.3. (B,D) The same experiment was repeated 5 times for each condition. Each symbol $(+)$ represents the measurement performed on a single D1 MSN, displayed in a same color for a same experiment. 

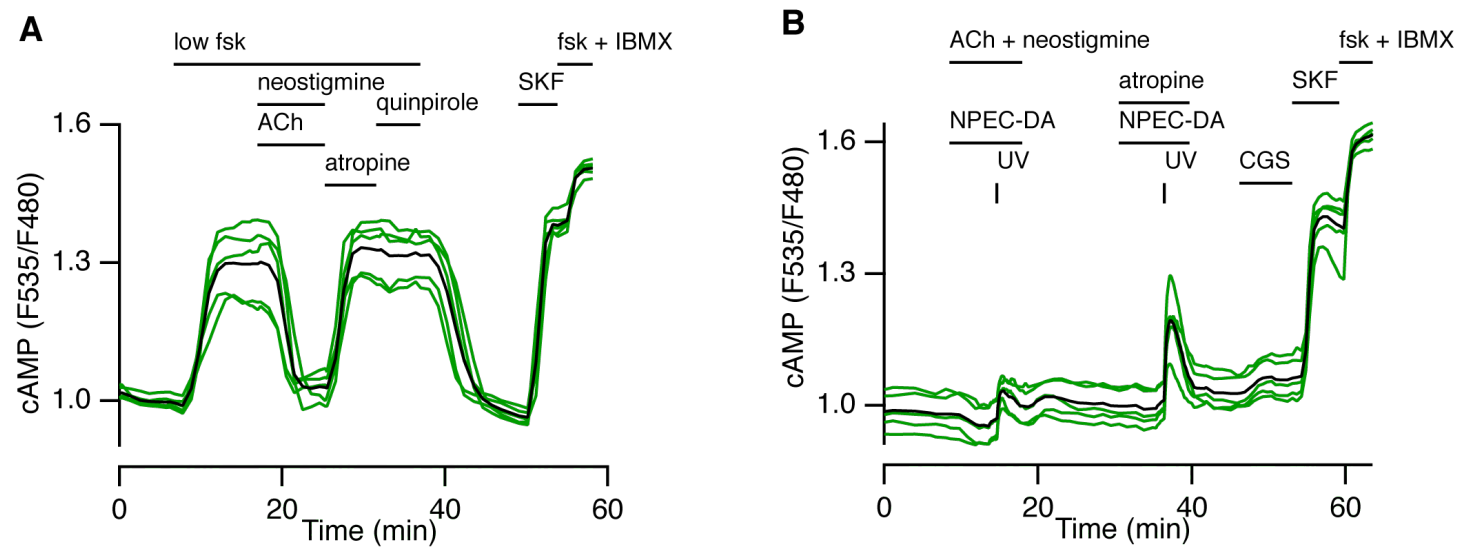

\section{FIGURE 4: ACETYLCHOLINE SUPPRESSES THE RESPONSE TO DOPAMINE.}

Striatal brain slices were imaged with wide-field microscopy expressing the cAMP biosensor Epac- $\mathrm{S}^{\mathrm{H} 150}$ (A, B) or the AKAR3 biosensor which reports the PKA/phosphatase equilibrium (C). (A) A low concentration of forskolin (low fsk, $250 \mathrm{nM}$ ) was applied to increase cAMP production. In the presence of the acetylcholinesterase inhibitor neostigmine $(1 \mu \mathrm{M})$, application of acetylcholine (ACh, $100 \mathrm{nM})$ decreased cAMP, an effect that was reversed by atropine $(2 \mu \mathrm{M})$. Quinpirole $(1 \mu \mathrm{M})$ had no effect whereas SKF-81297 (SKF, 100 $\mathrm{nM}$ ) increased cAMP, confirming the D1 identity of the recorded neurons. (B) $1 \mu \mathrm{M}$ caged dopamine (NPEC-DA) was applied in the bath together with acetylcholine and neostigmine. Uncaging dopamine with a flash of UV light produced little cAMP response. A second uncaging in the presence of atropine produced a cAMP response that was larger than the first one. Lack of response to CGS and positive response to SKF confirmed the D1 identity of the recorded neurons. 
A

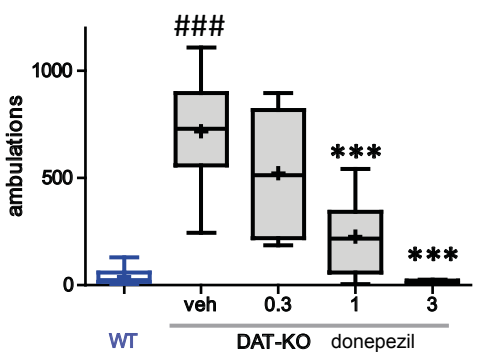

C

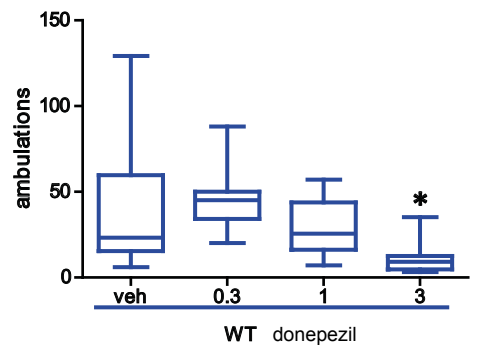

$E$

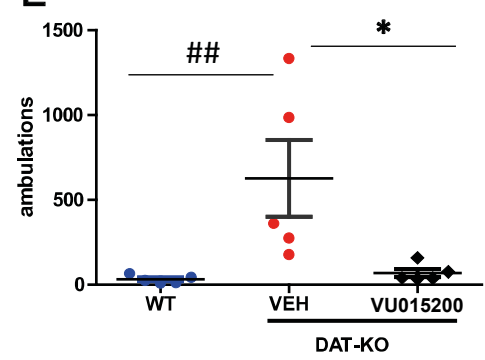

B

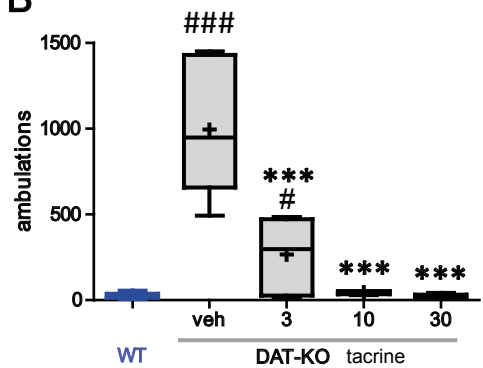

D

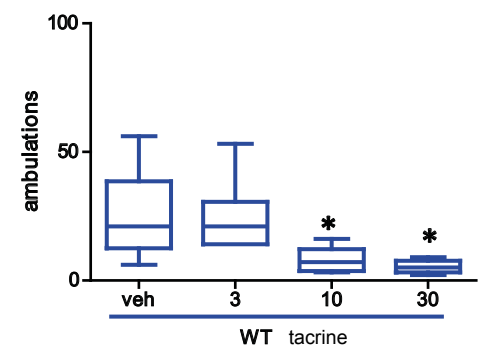

$\mathrm{F}$

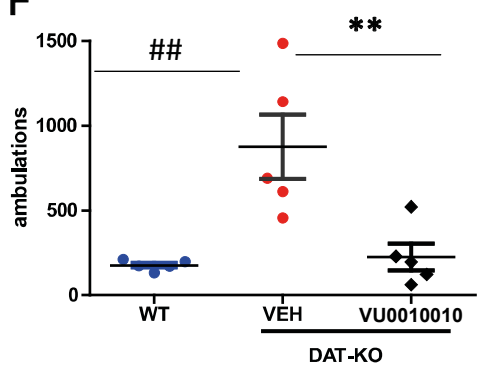

\section{FIGURE 5: ACETYLCHOLINE DECREASES SPONTANEOUS HYPERLOCOMOTION IN DAT-KO MICE VIA STRIATAL M4 RECEPTORS.}

The acetylcholinesterase inhibitors donepezil $(\mathrm{A}, \mathrm{C})$ and tacrine $(\mathrm{B}, \mathrm{D})$ dosedependently reduce spontaneous hyperlocomotion in DAT-KO mice (A,B) and at higher doses in WT counterparts (C,D) (indicated doses are in $\mathrm{mg} / \mathrm{kg}$ i.p.). This effect was mimicked by an M4-receptor positive allosteric modulator administered either i.p. (E; VU0152100; 1 $\mathrm{mg} / \mathrm{kg}$ ) or locally in the striatum (F; VU0010010; $1 \mu \mathrm{L} / 10 \mu \mathrm{M}$ bilateral infusion). $\# \mathrm{p}<0.05$; $\# \# \mathrm{p}<0.01 ; \# \# \# \mathrm{p}<0.001$ vs WT treated with same dose; ${ }^{*} \mathrm{p}<0.05 ;{ }^{*} \mathrm{p}<0.01 ; * * * \mathrm{p}<0.001 \mathrm{vs}$ same genotype treated with vehicle. Data in all panels were analyzed with one-way ANOVA and Duncan's post hoc. 